\section{Lessons from the Past*}

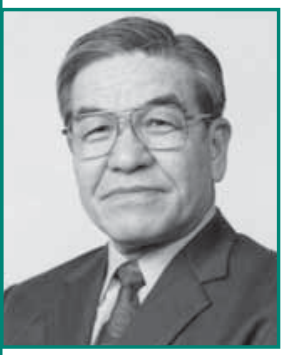

by Hitoshi Ohtaki+

his article briefly reviews the development of science and technology in Asia, mainly in Japan. It focuses on why science and technology in Japan were able to develop after the catastrophic damage of the Second World War. Since this paper was read at the 9th Eurasia Conference on Chemical Sciences, an emphasis is placed on the relationship between Asian and Western countries.

Japan was an underdeveloped country in science and technology 150 years ago, although mathematician Kowa Seki and physicist Gennai Hiraga did make important contributions around that time. Japan had been isolated from other countries for 300 years during the Tokugawa Period until the Meiji Era, which began in 1852. During this period, Japan had practically no exposure to European and American science, technology, or culture. On the other hand, the characteristic culture of Japan had been blooming during this period.

Other Asian countries, which were controlled by suzerain states at that time, were much more enriched in modern science and technology than Japan. However, in most case the science and technology were exclusively used by the suzerains, and the native people did not share in its benefits.

\section{Modern Chemical Sciences in Japan}

Many technological advances occurred in Asia before the advent of modern chemistry. For example, gunpowder originated in China in the 7th century-much earlier than in Europe where it was not produced until the 13th century. Further improvements in gunpowder

*The full version of this paper is included in the Proceedings of the 9th Eurasia Conference of Chemical Sciences, to be published by Springer-Verlag, under the title "Innovations in Chemical Biology." (See conference report in Mar-Apr 2007 Cl, p. 24.)

+Hitoshi Ohatki passed away on 5 November 2006, a few days after submitting this paper to $\mathrm{Cl}$. Ohtaki was a professor in the Department of Applied Chemistry of the Faculty of Science and Engineering at Ritsumeikan University, in Kusatsu, Japan. were made by Masachika Shimose (1859-1911), who used picric acid instead of nitrocellulose. This advance is credited with helping the Combined Fleet of Japan, commanded by General Togo, beat the Baltic Fleet of Russia in a 1905 Japan Sea battle at the end of the Russo-Japanese War.

\section{A Period of Modernization}

A systematic investigation of the chemical sciences of Japan was started by Yoan Udagawa (1798-1846; right), who was influenced by the books of Antoine Laurent Lavoisier. In 1837 he published the first Japanese chemistry textbook, which was entitled Seimi-Kaiso or "Opening of Chemistry." "Seimi" comes from the pronunciation of "chemie" in Dutch. See photo on page 13.)

The Isolation Policy of Japan started at the begin-

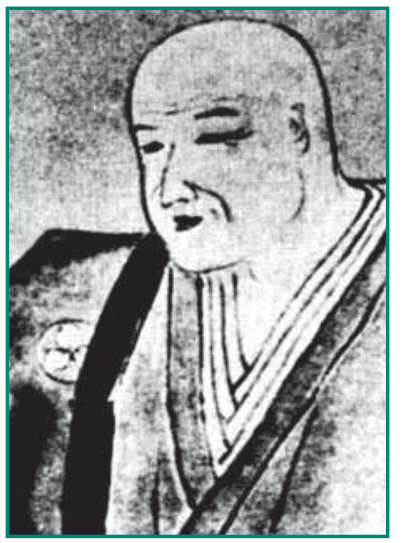

Yoan Udagawa ning of the 17th century and ended in 1854. In 1853, four Black Ships directed by U.S. Commodore Matthew C. Perry (1794-1858) visited Uraga, a small town near Yokohama. Commodore Perry's superior military force enabled him to negotiate a treaty allowing American trade with Japan, ending a 200-year period in which trading with Japan was only allowed to the Dutch, Chinese, and a few other small groups. The following year, at the Convention of Kanagawa, Perry returned with seven ships and forced the shogun to sign the "Treaty of Peace and Amity," establishing formal diplomatic relations between Japan and the United States.

Foreign Teachers of Science and Technology

In 1867, soon after the end of the Tokugawa Period (Edo Era), a new government under the Meiji Emperor began. During this era, the government launched a campaign to modernize the country and elevate Japanese culture to the level of European culture, especially in the area of science and technology. As part of this effort, the government invited about 3000 foreign teachers to private schools in various parts of Japan. Their monthly payments were comparable to those of government ministers. In 1868, the first university in Japan was established: the Imperial University of Tokyo.

Science and Technology Textbooks in Japanese 
Chemistry textbooks were introduced to Nagasaki by Dutch, German, and French doctors. Some of them were translated into Japanese. In 1861, Komin Kawamoto (1810-1871) published Kagaku Shinsho (New Chemistry), which is a Japanese translation of The School of Chemistry (1846), written by J.A. Stöckhardt (Germany), which was translated from the Dutch book Inorganic and

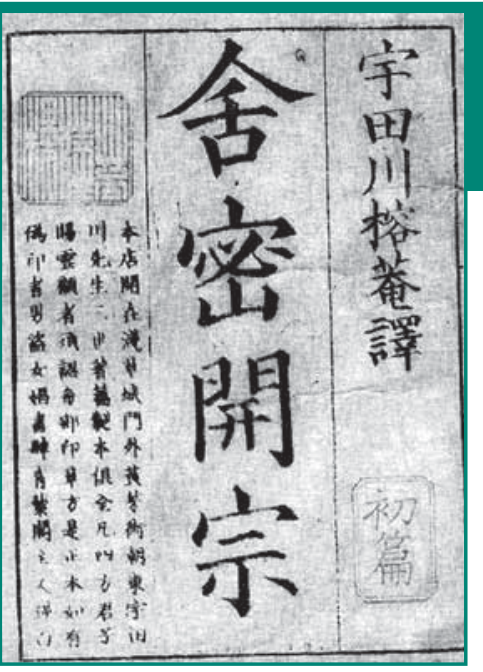

Seimi-Kaiso, the first Japanese chemistry textbook.

Organic Chemistry by J.W. Genning (Holland) in 1850. Teizo Kono (1817-1871) published 14 volumes of Seimi Binran (Handbook of Chemistry) in 1856.

\section{Students Study Science and Technology Abroad}

During the Meiji Period, many students were sent to European countries to study in various fields. The Japanese government's investment in these educational activities amounted to about one-third of the total budget of the Ministry of Education. However, the investment paid off as a number of

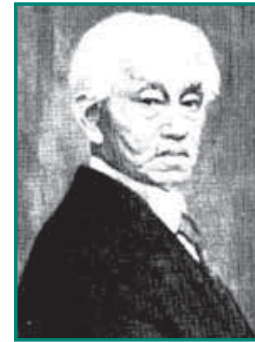

Nagayoshi Nagai. these students went on to become scientific leaders during the Meiji (18681912) and Taisho (1912-1926) Eras. Among them was Nagayoshi Nagai (1845-1922, left) who studied chemistry in the laboratory of A.W. Hofmann (1819-1892) at the University of Berlin, Germany, and discovered ephedrine in 1885.

Another of these students was Joji Sakurai (1858-1939), who went to London in 1878 to study chemistry under A.W. Williams (1824-1904). When he returned to Japan in 1881, he was immediately appointed a lecturer and soon promoted to a professor at the Imperial University of Tokyo. His contributions to the development of chemistry, especially his leadership as president of the Chemical Society of Japan, which was established in 1878, and as the president of the Japan Academy (established in 1879), are especially noteworthy.

Kikunae Ikeda (1864-1936, right) was interested in physical chemistry, a new and rapidly progressing field of chemistry in Europe, and studied reaction kinetics and catalytic reactions in the laboratory of F.W. Ostwald (1853-1932) of the University of Leipzig, Germany, from 1899 to 1901. Ikeda became a professor of physical chemistry at the Imperial University of Tokyo, but he is much better known as the discoverer of

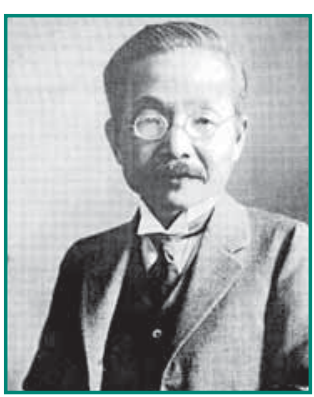

Kikunae Ikeda. glutamic acid, which he extracted from sea weed, and as inventor of the seasoning "Aji-no-Moto" or sodium glutamate.

In 1900, after Umetaro Suzuki (1874-1943, below) had graduated from the Agricultural College of the Imperial University of Tokyo and became an associate professor, he went to ETH of Zurich, Switzerland, to work with E.A. Schlze. Next he worked in the laboratory of E. Fischer (1852-1910) of the University of Berlin from 1901 until 1906. After this, he was appointed as a professor at the Agricultural High School of Morioka. His observations of the nervous system disorder beriberi in chickens resulted in the discovery of oryzanin (vitamin B1) in 1910, which is an extract from rice bran.

\section{After WWII}

After the United States dropped atomic bombs on Hiroshima and Nagasaki in 1945 , the damage was so catastrophic in all parts of Japan that schools and universities were almost completely closed. Eventually, with support from the U.S. government and U.S. nongovernmental organizations, these schools were

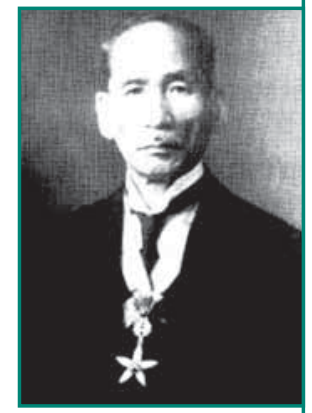

Umetaro Suzuki. able to reopen. This kind of support was extended to scientific studies. One of the most well-known U.S. organizations to help was the Fulbright Foundation, which made it possible for many young and middleaged scientists to study in the USA. Prior to WWII, most Japanese scientists who studied abroad went to Europe. After World War II, probably more than 80 percent of Japanese researchers went to the USA to study science and technology.

In 1955, the Japanese economy was so bad that the monthly stipend for a university research associate who was about 30 years old was only USD 30. The rapid recovery that the Japanese economy achieved by the 1970s was supported by science and technology development.

Today, the Japanese government still understands the importance of fundamental research, applied science, and technology. Funding for the promotion of scientific research was 188 billion Yen (USD 1.65 billion) in 2005. However, as an increment of the total government budget,

\section{continued on page 18}

